\title{
Development of a powder warming compacting machine with an electrical heating system
}

\author{
C.Y. Lung ${ }^{\text {a }}$, K.C. Fan ${ }^{\mathrm{a}, *}$, J. Mou $^{\mathrm{b}}$, W.B. Liao ${ }^{\mathrm{c}}$ \\ ${ }^{a}$ Department of Mechanical Engineering, National Taiwan University, Taipei, Taiwan, ROC \\ ${ }^{\mathrm{b}}$ Department of Industrial Engineering, Arizona State University, Tempe, AZ, USA \\ ${ }^{\mathrm{c}}$ Lenco Enterprises Co., Ltd., Toufen, Miaoli, Taiwan, ROC
}

Received 26 December 2001; received in revised form 31 May 2002; accepted 3 June 2002

\begin{abstract}
Density control is an important factor in producing high-quality powder metallurgy parts (P/M). All mechanical properties are improved with increased density. To obtain parts with higher density, the double-pressing, double-sintering, and powder forging or copper infiltration methods are usually applied. However, the operation cost also increases from $40 \%$ to $100 \%$. Recently, suppliers of $\mathrm{P} / \mathrm{M}$ material and compacting presses have cooperated to develop warm compacting technology that increases the density of powder metal parts from 7.1 to $7.2-7.5 \mathrm{~g} / \mathrm{cm}^{3}$ with a single press and single sintering cycle while keeping the operation cost increase below $20 \%$.

This paper presents a new powder heating method with an electrical heater element instead of the hot oil circulation process that is currently used in warm compaction. This electrical heating system simplifies the heating element installation and can be fitted to all types of presses. This system is easy to maintain and operate, and could significantly reduce production costs.
\end{abstract}

(C) 2002 Elsevier Science B.V. All rights reserved.

Keywords: Powder metallurgy; Warm compacting; Electric heater

\section{Introduction}

Metal powders are usually cold-welded together, when compacted in a mold with applied pressure to increase the green strength of the compacted powder part. When the green strength is above $27.6 \mathrm{MPa}$, the compacted metal powder part can be manufactured directly. This method is simpler and cost less than remanufacturing a sintered part $[1,2]$. Capus [3] presented warm compacting technology in 1994. In 1995, Howard and Francis [4] compared the cost of producing iron metal powder parts with warm compacting technology and traditional production technology. Warm compacting not only cost $50-80 \%$ less than mechanical cutting and cold working, but also promoted 10-30 times the production efficiency. In the same year, an American company, Höganäs, introduced the Ancordense warm compacting technique.

Many researchers have studied the development of warm compacting for powder forming in recent years. In 1997, \footnotetext{
1755.

* Corresponding author. Tel.: +886-2-2362-0032; fax: +886-2-2363-

E-mail address: a6677a@ms23.hinet.net (K.C. Fan).
}

Luk et al. [5] indicated that increasing the temperature reinforces the green strength of the compacted part better than increasing the compacting pressure. Metal powder strain hardening will also decrease with the increase in compacting temperature. Therefore, for most metal powders, a higher density can be obtained with the same compacting pressure [6]. Since 1998, warm compacting with hot oil circulation for process preheating has been widely adopted [7]. Raffeinner [8] compared auger system, oil-filled system, fluidized bed system, and microwave system for their pros and cons, and proposed that a better warming compacting system requires the consideration of issues such as heating temperature uniformity, less operating skill, easy installation and configuration, good insulation effect, low power consumption, and operating safety of the system. Kondoh et al. [9] indicated that when the preheat temperature of warming compacting system is below the melting point of lubricant, the fractional volume compaction is mainly influenced by particle rearrangement. Therefore, there is a good relation between fractional volume compaction, green density, and compacting pressure. However, when the temperature is above the melting point of the lubricant, its lubrication to particles becomes unstable, and 
then the negative effect generates. Consequently, attention should be focused when selecting lubricant for conducting warming compacting to metal powders.

Heating mediums such as microwave, infrared, and oil are used in metal powder heating. When a metal's presence is in powder form, it can absorb much microwave radiation to heat the metal powder. However, the cost of a microwave system is relatively high, and the heat absorbed by powders will dissipate through the inner wall of the microwave oven with improper insulation. Oil warming is widely used because it is not only safer, but also costs less in terms of the equipment and maintenance than a microwave warming system. Oil warming systems are more easily adapted to factory environments. However, hot oil circulation still has some drawbacks that need to be improved. They are:

1. A heat pump is used to constantly circulate high temperature oil through the metal powder. The power consumption is high due to the low thermal conductivity of oil.

2. High temperature oil requires stringent safety protection to avoid personnel injuries when leakage occurs.

3. The oil quality deteriorates under continuous operation at high temperatures.

4. The cost of a hot oil circulation system is relatively high. These are the development goals of this system.

\section{Metal powder heating system}

The critical parameters for a metal powder heating process are temperature and time. If the heat distribution is non-uniform or when a large temperature gradient exists, the powder might stick together, reducing the fluidity of the powder, causing difficulty in forming the green compact or decreasing the quality of the compact. The thermal conductivity of a common metal powder is much worse than that bulk metal. Thus, to shorten the warming time, the heat distribution should be uniform, the powder surface contacting the heat source should be large, and the distance between the heat source and the die should be minimum. Fig. 1 shows a typical powder preheating system in which the metal powder is first heated in a main heater zone, then delivered by hose through a feedshoe to the die, and finally compacted.

\subsection{Oil warming process control analysis and the design of electric heating system}

In an oil warming system, a heater warms the circulating oil in the tank first. The hot oil is then pressurized by a pump and moved through a circulation hose to deliver the heat to the metal powder. The oil is eventually recirculated back to the oil tank for continuous heating. This oil is heated and circulated in a closed system.

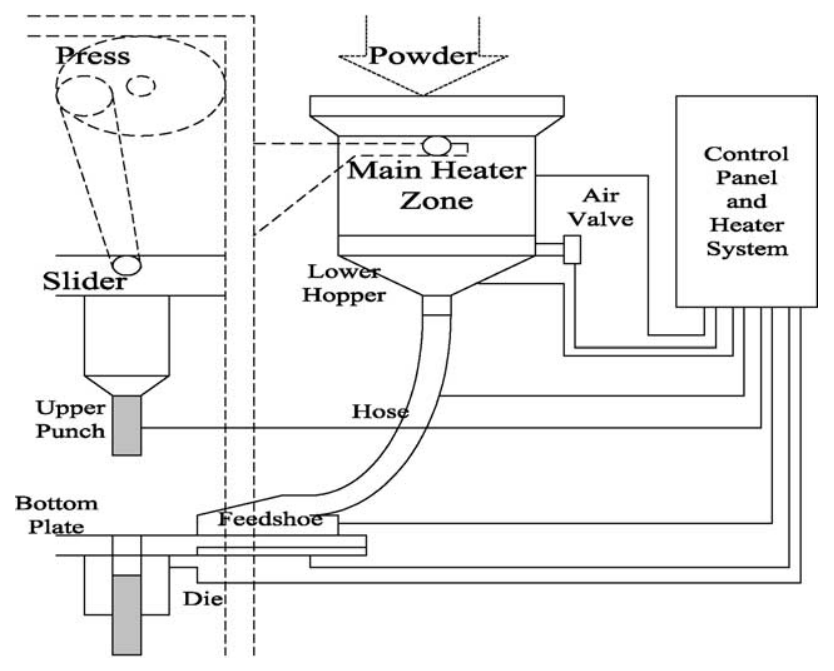

Fig. 1. Powder preheating system.

Considering mass conservation, mass accumulation is given by:

$\frac{\mathrm{d}(v \rho)}{\mathrm{d} t}=W_{i}-W$,

where $\rho$ is the density of the circulated oil, $W_{i}$ is the circulated oil input rate, $W$ is the circulated oil output rate, and $v$ is the volume of oil.

By energy conservation, energy accumulation is given by:

$$
\begin{aligned}
C \frac{\mathrm{d}\left[v \rho\left(T-T_{\text {ref }}\right)\right]}{\mathrm{d} t}= & W_{i} C\left(T_{i}-T_{\text {ref }}\right)+Q-W C\left(T-T_{\text {ref }}\right) \\
& -U A\left(T-T_{\mathrm{S}}\right),
\end{aligned}
$$

where $T_{\text {ref }}$ is the reference temperature of the enthalpy calculation, $T_{\mathrm{S}}$ is the ambient temperature, $A$ is the oil tank surface area, $U$ is the oil tank heat conductivity, $C$ is the heat capacity of oil, $T_{i}$ is the hot oil temperature when it feeds back into the oil tank, $v$ is the volume of oil, $Q$ is the energy rate from the heater to the oil tank, and $T$ is the hot oil temperature when it exits the oil tank.If the circulation oil density and heat capacity are constant, and the oil tank is well insulated, heat loss can be ignored and $U A\left(T-T_{\mathrm{S}}\right)$ can be neglected and the heat capacity remains constant, then the control mode will be as follows:

$\frac{\mathrm{d} v}{\mathrm{~d} t}=\frac{1}{\rho}\left(W_{i}-W\right)$

$\frac{\mathrm{d} T}{\mathrm{~d} t}=\frac{W_{i}}{v \rho}\left(T_{i}-T\right)+\frac{Q}{v \rho C}$.

If the circulated oil input rate $W_{i}$ equals the output rate $W$, and the circulated oil volume $v$ is constant, Eq. (4) will be a first-order ordinary differential equation that can be solved as follows:

$T=T_{i}+\frac{Q}{C W_{i}}\left(1-\exp \left(\frac{-W_{i} t}{v \rho}\right)\right)$. 
According to the above derivation, when the system control process changes, the control parameters will be changed from one steady state to another.

The same temperature control mode was adopted in the electric heating system design for powder preheating. The designed heating structure is shown in Fig. 2. The electric heater was put into a stainless heating box and sealed. When the electrical power is on, the heater can warm the air inside the sealed space. Stainless steel has poor thermal conductivity, and the sealed section is required to maintain the temperature. Therefore, for a narrow heating box, the air inside can be quickly heated to a specified temperature if the proper electrical heater is chosen. As the air reaches the target temperature, the heat is conducted through a stainless steel shell to increase the powder temperature.

If several stainless heating boxes are installed in parallel inside the powder container, the powder can be uniformly heated within a short time. The throughput of the hot powder can be increased to meet the production demand by using greater numbers of stainless steel heating boxes. The structure of assembled system is shown in Fig. 3.

Another design factor that must be considered is the gap between the heating boxes that is influenced by the electrical heater power, preheating time, powder particle size, and heating surface contact resistivity. The air trapped between the powder particles will lead to a lower metal powder thermal diffusivity. The thermal diffusivity is defined by $\alpha=\kappa / \rho c$, where $\kappa$ is the thermal conductivity, $\rho$ is the density, and $c$ is the specific heat. In general, the thermal diffusivity of bulk metal is about $20.7 \mathrm{e}-6 \mathrm{~m}^{2} / \mathrm{s}$ at $27^{\circ} \mathrm{C}$. On the other hand, the thermal diffusivity of powder metal is about $39 \mathrm{e}-6 \mathrm{~m}^{2} / \mathrm{s}$ at $27{ }^{\circ} \mathrm{C}$, which is almost twice that for bulk metal. Therefore, the required heating time for powder metal to reach the same temperature is greater.

According to the principle of energy consistency with the presumption of adequate insulation, the energy input must be equal to the powder energy absorption as follows [7]:

$E=\left[\left(V \cdot \rho \cdot C_{\mathrm{p}} \cdot \Delta T\right) / t\right] \cdot \mathrm{SF}$,

where $E$ is the electrical heater power, $V$ is the space volume between two heating boxes, $\rho$ is the metal powder density, $C_{\mathrm{p}}$

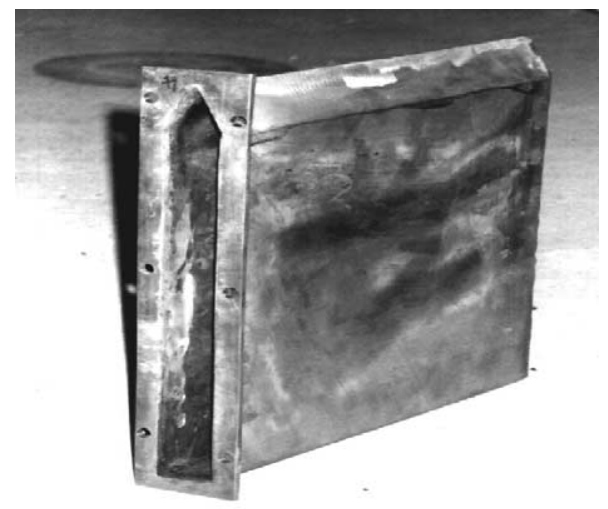

Fig. 2. Stainless heating box.

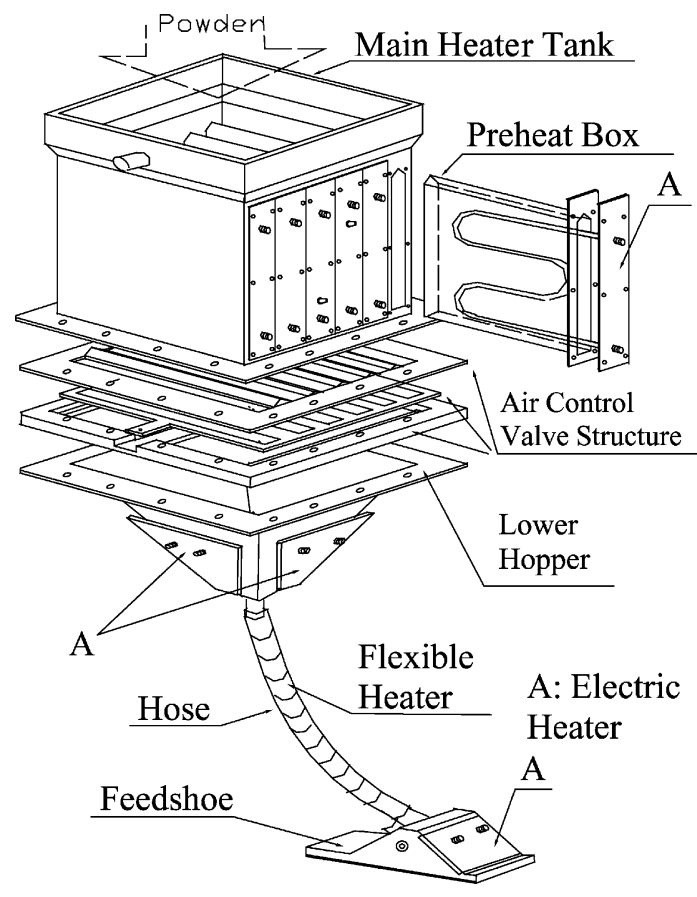

Fig. 3. Assembled system structure.

is the metal powder heat capacity, $\Delta T$ is the temperature increase, $t$ is the heating time, SF is the design safety factor $(\cong 2)$.

If the designed heater power, heating time, preheating, and gap between the heating boxes can satisfy the above condition, the temperature control process can be optimized.

After the powder is preheated in the main heating tank, the pneumatic valve can be opened to allow the powder to drop into the lower hopper ready for compaction. The function of the lower hopper is to preserve the preheated powder to prevent energy loss through conduction. By installing plate heaters on the hopper's inner wall and insulated material on the hopper's outer wall, sufficient thermal energy can be maintained in the preheated powder.

\subsection{Hose and feedshoe design}

A hose is used to connect the lower hopper and feedshoe of the compacting machine. The temperature of the preheated powder is about $135{ }^{\circ} \mathrm{C}$. A silicon pipe that can withstand temperatures above $180{ }^{\circ} \mathrm{C}$ was chosen as the hose material. In order to keep the metal powder at the compacting temperature, the powder feed hose is wrapped with a flexible heater and covered with glass fiber insulation material to achieve heat preservation and prevent heat loss.

The feedshoe provides the powder for filling the die cavity and the horizontal pushing force for separating the compacted green part from the die. Due to limited space, the preheated powder will only stay in the feedshoe for a short time. Moreover, the bottom plate of the compaction 
die could be fitted to supply additional heat to the metal powder. Thus, only a low power heater plate was installed on the feedshoe to keep the powder temperature at $130{ }^{\circ} \mathrm{C}$.

\subsection{Die and bottom plate heating system}

There are two major factors that must be considered in die heating system design. The first is the required heat source and time to heat the die from room temperature to working temperature. The second is the heat loss when the die is heated to a steady state temperature.

Due to the uncertainties related to the die geometry and the compacting operational condition, the required energy can be calculated using the nominal heat transfer estimation method first, and then a proper safety factor (SF) can be chosen to fine-tune the required heat source per unit time. If there is no heat loss during die warming, the die-heating rate could be defined as follows [7]:

$P=\left[\left(m \cdot C_{\mathrm{p}} \Delta T\right) / t\right] \cdot \mathrm{SF}$,

where $P$ is the power of the heating source, $m$ is the mass of the heating die, $C_{\mathrm{p}}$ is the die heat capacity, $\Delta T$ is the temperature increase, and $t$ is the heating time.

In practice, the higher the die temperature, the more heat loss involved. When the die temperature reaches steady state, the heat loss will also become stable. To ensure compacting efficiency, the time for die heating has to be much shorter than the time for heating the metal powder from room temperature to working temperature.

When the die is heated to a steady state temperature, the die heat loss can be expressed in terms of heat conduction, convection, and radiation, respectively, as follows [7]:

Loss through heat conduction : $P_{\text {conduction }}=A(K / \Delta x) \Delta T$,

Loss through heat radiation : $P_{\text {radiation }}=A \varepsilon \sigma\left(T_{1}-T_{2}\right)$,

Loss through heat convection : $P_{\text {convection }}=A h\left(T_{1}-T_{2}\right)$,

where $A$ is the die area exposed to ambient air, $K$ is the die heat conduction coefficient, $T_{1}$ and $T_{2}$ are the die and the ambient temperatures, respectively, $\Delta T$ is the temperature difference, $\varepsilon$ is the heat radiation coefficient, $h$ is the heat convection coefficient, $\sigma$ is the Stefan-Boltzmann constant, and $\Delta x$ is the distance from the heat source.

The heat loss expressed in Eqs. (8)-(10) will have different temperature gradients due to the differences in die shapes and geometric symmetry [5]. The heat loss due to radiation and convection will be much less than the loss caused by heat conduction under steady compaction condition and low air circulation, and thus, can be ignored.
To consider the convenience of placing the heater and temperature sensors around the existing compacting equipment and die, a removable ring-shaped heater was adapted for upper and lower punch seats. Thus, the size and frame width must be matched with the outer diameter of the upper and lower punch seats.

After the feedshoe completes the die-filling task, it stations itself at the rear end of the bottom plate, where the powder temperature will drop quickly. In order to maintain the powder temperature and avoid modifying the mechanical structure of the bottom plate, a plate-type and removable heater were adapted.

\subsection{Choice and features of temperature sensor}

The temperature changes in different sections of the heater are monitored with temperature sensors. These sensor signals are transformed into corresponding temperature information. The upper temperature range for the developed system is between 150 and $180{ }^{\circ} \mathrm{C}$. The J-type thermocouple was adopted because it is widely used by the industry, is low priced, has good reliability, and is suitable for a hostile working environment. Its output voltage corresponding to temperature increase is greater than the K-type thermocouple and leads to a better resolution. For the die heating plate, fillshoe, and supply hose, the thermocouples are individually wired. For the heaters in the main preheating zone and lower hopper, the thermocouples are wired in parallel to measure the temperature at different sections, and then derive the mean temperature.

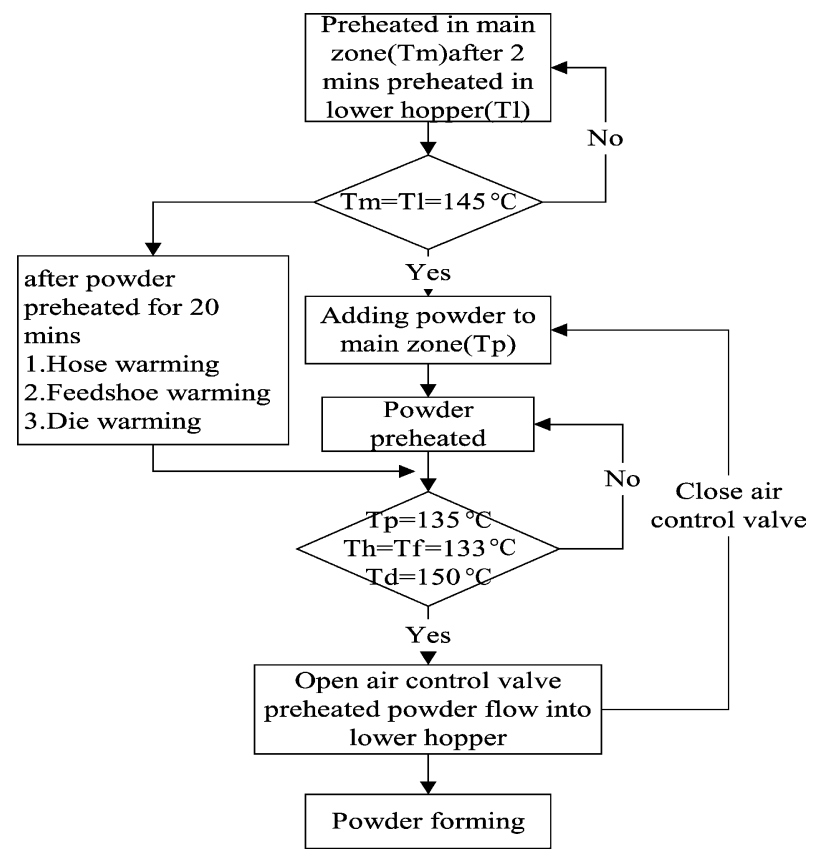

Fig. 4. Flow chart of temperature controlling system (temperatures are at $T_{\mathrm{m}}$ : preheated in main zone, $T_{1}$ : lower hopper, $T_{\mathrm{p}}$ : powder, $T_{\mathrm{h}}$ : hose, $T_{\mathrm{f}}$ : fillshoe, and $T_{\mathrm{d}}$ : die). 
Table 1

Power and heater shape for various heating areas

\begin{tabular}{llll}
\hline Heating area & Power $(\mathrm{W})$ & Heater sets & Heater shape \\
\hline Lower hopper & 150 & 4 & flat \\
Hose & 350 & 1 & flexible \\
Fillshoe & 200 & 1 & flat rectangle \\
Upper punch & 200 & 1 & ring \\
Lower punch & 200 & 1 & ring \\
Bottom plate & 250 & 1 & flat rectangle \\
Main preheating zone & 350 & 6 & AH spiral hose \\
\hline
\end{tabular}

\subsection{Temperature controlling system}

To control the temperature changes in various sections within the range of $\pm 1{ }^{\circ} \mathrm{C}$ while considering the characteristic of each heater and different temperature increase rate, severe temperature oscillations at various sections might occur if only an ordinary on/off control mode is used. To ensure that the heater quickly reaches the steady state temperature, an auto-tuning PID controller was adopted and coupled with the proper heater power parameter as well as responsive thermocouples to form a closed-loop control system. The system temperature control flow chart is shown in Fig. 4.

\subsection{Heater design}

When a high power heater is selected, the potential for excessive temperature fluctuations may exist. On the other hand, with a low power heater, the targeted heating temperature may not be reached or prolonged heating time might be required. Distaloy $\mathrm{AE}$ powder from Höganäs has an apparent density of about $3.1 \mathrm{~g} / \mathrm{cm}^{3}$ with a maximum volume of $0.0081 \mathrm{~m}^{3}$ in the preheating zone. When the $\mathrm{SF}$ is set to 2 , to heat the powder from 20 to $150{ }^{\circ} \mathrm{C}$ within $30 \mathrm{~min}$, the required power at the main heater zone is 1.7 $\mathrm{kW}$. The heating source comes from six sets of heaters, and thus every heater needs $300 \mathrm{~W}$. When the system operates at a steady temperature situation, the heaters need extra power to compensate for the heat loss. Thus, the power for each stainless steel heater should be $350 \mathrm{~W}$, with a three-phase

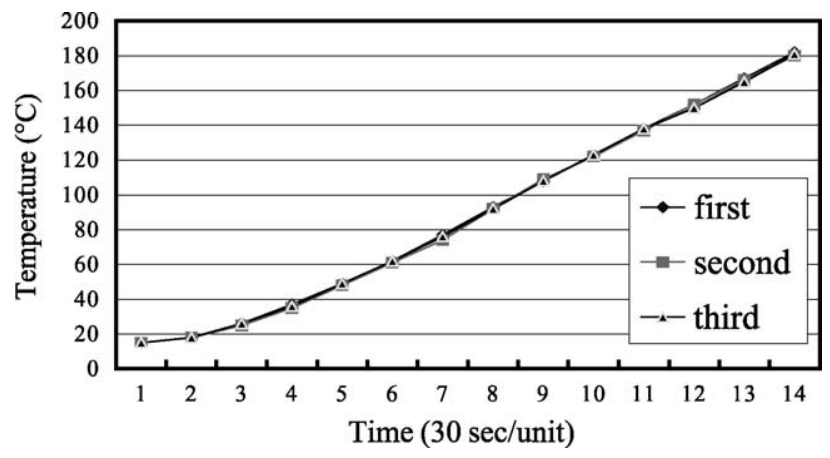

Fig. 5. Temperature rise repeatability curves of the container in the main preheating zone.

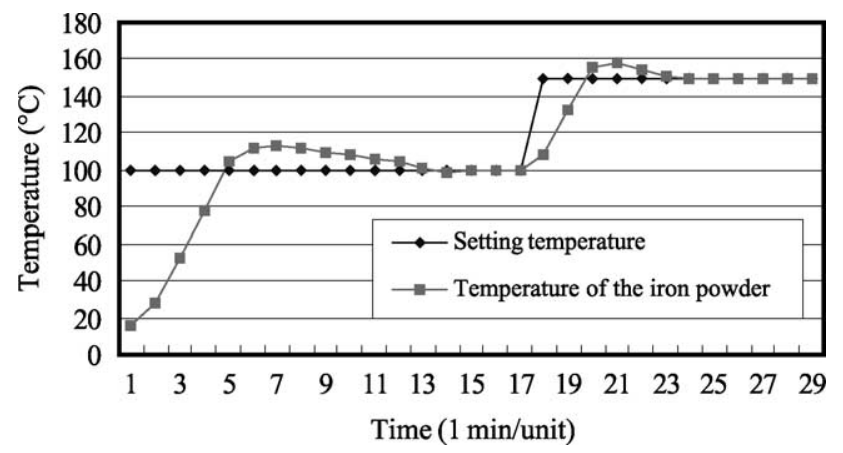

Fig. 6. Self-control dynamic mode of the temperature at the main preheating zone.

220 V source power. Similarly, other heaters will supply heat to warm various sections from 130 to $150{ }^{\circ} \mathrm{C}$ when compensating for the heat loss during operation. Therefore, the heat loss through conduction from various sections must be considered when calculating the power by multiplying the proper safety factor. The results are shown in Table 1 .

\section{Heater property analysis and temperature set-up}

A three-phase, $\triangle$-type connection, $220 \mathrm{~V}$ heater is used for the main preheating area. As shown in Fig. 5, the temperature at the preheating area of the container has good repeatability between 15 and $180{ }^{\circ} \mathrm{C}$ in three discrete heatings. The results show that the heater has nearly linear repeatability for temperature increases between 100 and 180 ${ }^{\circ} \mathrm{C}$. When the temperature is set at $100{ }^{\circ} \mathrm{C}$, the temperature of iron powder in the main preheating zone area will reach $100{ }^{\circ} \mathrm{C}$ within $10 \mathrm{~min}$. If the temperature continues to increase to $150{ }^{\circ} \mathrm{C}$, the temperature of the iron powder in the main preheating zone will reach another steady state within an additional $5 \mathrm{~min}$. The results show that with proper main preheating zone design and thermocouple placement selection, a satisfactory self-control process mode can be derived, as shown in Fig. 6.

According to the metal powder features from Höganäs [10] and Distaloy $\mathrm{AE}+0.3 \% \mathrm{C}+0.6 \%$ lubricant, both the

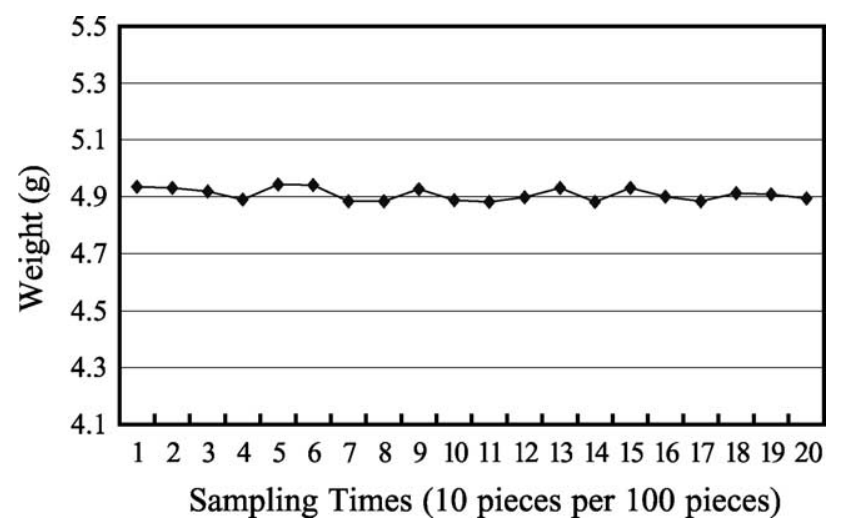

Fig. 7. Parts weight changes. 


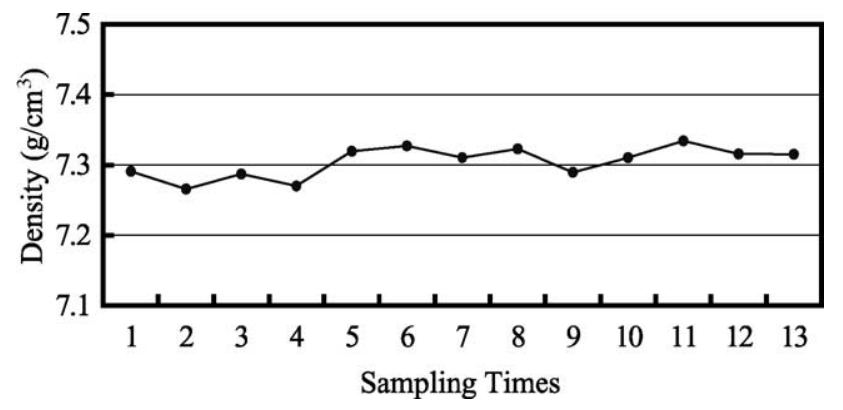

Fig. 8. Density of sintered parts with oil impregnation.

apparent density and the powder fluidity are very stable and insensitive to temperature variations up to $135{ }^{\circ} \mathrm{C}$. However, at temperatures above $135{ }^{\circ} \mathrm{C}$, these two properties will change as the apparent density decreases and the fluidity increases. The powder filling behavior becomes worse, resulting in increasing variations in weight and tolerances in the compacted parts. The proper compacting temperature is between 130 and $135{ }^{\circ} \mathrm{C}$. According to empirical experience, the temperature setting for the main preheating zone should be about $145{ }^{\circ} \mathrm{C}$, the temperature setting for the punch and die should be about $150{ }^{\circ} \mathrm{C}$, and the temperature setting for the other sections should be around $130{ }^{\circ} \mathrm{C}$.

\section{Experimental results}

Compared to the conventional oil heating system, the system's temperature control is handled by an auto-tuning PID control, and its deviation range can be controlled within $\pm 1{ }^{\circ} \mathrm{C}$. Based on the research results of CooperEaton equations conducted by Kondoh et al. [9], when below the melting point of lubricant, the temperature change in relation to the fractional volume compaction, and coefficient of particle rearrangement is a direct ratio, thus enhancing the stability of the system for the size and density quality of forming parts. In addition, the first mass production test conducted by Lenco Enterprises has gained the required quality lever of the industry [11].

This powder preheating system was installed on a 20-ton press using the floating die technique. The compacted part is a ring with $6 \mathrm{~mm}$ height, $7 \mathrm{~mm}$ inner diameter, and $14 \mathrm{~mm}$ outer diameter. The compacting pressure is about $660 \mathrm{MPa}$ for Distaloy $\mathrm{AE}+0.3 \% \mathrm{C}+0.6 \%$ lubricant powder. Compacting speed is about 60 pieces $/ \mathrm{min}$. The compacted part weighs about $4.9 \pm 0.05 \mathrm{~g}$. The actual product weight variation is about $\pm 0.03 \mathrm{~g}$, as shown in Fig. 7. The standard deviation of height is $0.01 \mathrm{~mm}$. The process capability is 1.28 . The density of sintered parts with oil impregnation is $7.33 \mathrm{~g} / \mathrm{cm}^{3}$ with a standard deviation of 0.067 , as shown in Fig. 8. The average hardness (HRB) of the sintered part is $80.3 \pm 1.2$, which meets the requirement for mass production.

\section{Conclusions}

The averaged maximum powder weight in the main preheating zone is about $50 \mathrm{~kg}$. The averaged compacted part weighs $10 \mathrm{~g}$ for a 20 -ton compacting machine, and the production rate is $100 \mathrm{pieces} / \mathrm{min}$. If the machine is to be operated for $30 \mathrm{~min}$, the total amount of required preheated powder is $30 \mathrm{~kg}$, and the amount of powder leakage at the feedshoe and middle plate is about $50-150 \mathrm{~g} / \mathrm{min}$. The metal powder preheating capacity of the developed system is sufficient to meet the demand for continuous compacting production.

In summary,

(1) The experimental results show that the developed system can effectively increase the product density to the theoretical range.

(2) The system does not need devices such as oil pumps, circulation oil tanks, and leakage prevention for highpressure oil piping, and die heater mount. Therefore, the total development cost (including die design) is around onethird of the oil heating system with the same functionality.

(3) The PID temperature control system is more effective than the traditional control system.

(4) According to the product technical specifications of oil heating system of Linde Metallteknik [12], to preheat the metal powders in the unit of $70 \mathrm{~kg} / \mathrm{h}$, excluding the initial preheat time, it will require $4.053 \mathrm{~kW}$ power. This developed system needs only $2.15 \mathrm{~kW}$, thus saving power usage up to around $50 \%$.

(5) With a partially sealed narrow space air heating design, the required preheating time is shorter.

(6) The temperature control system can be flexibly adjusted according to the special requirement of different types of metal powders.

(7) The main function of the system is to control the temperature while performing the powder warming compacting process of metal powders for better product density, strength, quality, and stability. As for the dimensional precision of processed parts, further consideration should be taken to the die cavity variations caused by the thermal expansion.

\section{References}

[1] T.M. Cimino, S.H. Luk, Machinability evaluation of selected high green strength P/M materials, in: M. Phillips, J. Porter (Eds.), Advances in Powder Metallurgy and Particulate Materials, vol. 1, Metal Powder Industries Federation, Princeton, NJ, 1995, pp. 129-148, part 8.

[2] M.L. Shao, Producing process and material features influence on green compact, Bulletin of Powder Metallurgy Association 24 (1) (1999) 44-51.

[3] J. Capus, Höganäs offers higher density at lower cost, Metal Powder (1994) 49-58.

[4] G.R. Howard, G.H. Francis, High density processing of high performance ferrous materials, International Journal of Powder Metallurgy 31 (1) (1995) 97-108.

[5] S.H. Luk, F.Y. Chan, A.B. Davala, T.F. Murphy, Processing experi- 
ence of green strength enhanced materials system, in: Advances in Powder Metallurgy and Particulate Materials, vol. 3, Metal Powder Industries Federation, Princeton, NJ, 1997, pp. 33-53, part 16.

[6] R.M. German, Powder Metallurgy Science, Metal Powder Industries Federation, NJ, 1994, pp. 133-136.

[7] Höganäs, Warm compaction, Höganäs Handbook for Sintered Components (1998).

[8] T. Raffeinner, Warm compaction technology-powder heating technology, Advances in P/M Technology Seminar, December 2-3, 1997.
[9] K. Kondoh, T. Takikawa, R. Watnabe, Effect of lubricant on warm compaction behavior of iron powder particles, Journal of the Japan Society of Powder and Powder Metallurgy 47 (9) (2000) 941-945.

[10] Höganäs, Iron and Steel Powder for Sintered Components, PM 94-2, Höganäs (1999).

[11] J.H. Chen, S.F. Chen, Production experience of warm compaction, Bulletin of Powder Metallurgy Association 22 (3) (1997) 151-154.

[12] Linde Metallteknik, Slot Heater Warming Compacting Technical Specifications. 